\title{
Los convenios de asociación con entidades sin ánimo de lucro y su inclusión como modalidad en el estatuto general de la contratación estatal ${ }^{*}$
}

\author{
Nevis Acosta Suárez" \\ Martha Ligia Guarnizo Rojas
}

Recibido: 20 de agosto de 2019 • Aprobado: 18 de noviembre de 2019

\section{Resumen}

La figura de los convenios de asociación tiene su génesis en el artículo 355 de la Constitución política, reglamentado inicialmente por los decretos 777 y 1403 de 1992 y el decreto 2459 de 1993. Esta normatividad especial es anterior y ajena al estatuto contractual colombiano, en donde se consagró de manera particular y puntual el uso de esta tipología sin definir un procedimiento claro para la celebración de estos convenios, lo que implicó un amplio margen de discrecionalidad, por parte de la administración pública, en la escogencia de la EsAL, la determinación de los objetos y la práctica reiterada y común de esta figura de carácter exceptivo, lo cual generó el abuso en su aplicación. El Gobierno nacional, como consecuencia del

* $\quad$ Este artículo es producto del proyecto de investigación: "Los convenios de asociación con entidades sin ánimo de lucro, desde un enfoque equitativo, eficiente y eficaz de los recursos públicos”, gestionado en el marco del programa de la Maestría en Derecho Administrativo de la Universidad Libre, Bogotá D. C., Colombia.

Citar como: Acosta Suárez, N. y Guarnizo Rojas, M. L. (2020). Los convenios de asociación con entidades sin ánimo de lucro y su inclusión como modalidad en el estatuto general de la contratación estatal. Revista IUSTA, 52, 123-146. Dor: https://doi.org/10.15332/25005286.5486

** Abogada con formación y experiencia en Derecho disciplinario, administrativo, civil, procesal, contratación pública y derechos humanos, Máster en derecho administrativo y especialista en derecho constitucional. neas40@hotmail.com. orcid: 0000-0002-4424-6980.

*** Conciliadora en Derecho, con formación en derechos humanos, contratación pública y resolución de conflictos urbanos, con énfasis en el campo disciplinario y en la gestión de procesos contractuales, Especialista en Derecho procesal e instituciones jurídico-políticas y de derecho público, Máster en Derecho administrativo. marthalguarnizo@hotmail.com. orcid: 0000-0001-6492-7487. 
uso inadecuado de los convenios de asociación con entidades privadas sin ánimo de lucro, expidió una nueva reglamentación contenida en el decreto 092 del 23 de enero de 2017, que entró en vigencia el 1. ${ }^{\circ}$ de junio del mismo año. Con esta se derogan las anteriores reglamentaciones y se introduce la aplicación de los principios de la contratación estatal, así como el diseño de unos procedimientos contractuales con participación plural de las ESAL en casos específicos. Esto determina unos criterios de escogencia, desarrollados a través de una guía confeccionada por Colombia Compra Eficiente, que, si bien sirven de pauta y sugerencias, adolecen de carácter coercitivo y, por ende, mantienen un margen de discrecionalidad de los entes administrativos que impide una escogencia basada en criterios objetivos, esto es, libre de todo afecto o interés.

Palabras clave: Contratación estatal. Convenios de asociación. Entidades sin ánimo de lucro. Principios. Selección objetiva. Transparencia.

\title{
AsSOCIATION AGREEMENTS WITH NON-PROFit ORGANIZATIONS AND THEIR INCLUSION AS A MODALITY IN THE GENERAL STATUTE OF GOVERNMENT PROCUREMENT
}

\begin{abstract}
The figure of association agreements has its genesis in article 355 of the Political Constitution, initially regulated by decrees 777 and 1403 of 1992 and decree 2459 of 1993 . This special regulation is prior and alien to the Colombian contractual statute, where the use of this typology was established in a specific and detailed manner without defining a clear procedure for entering these agreements, which implied a wide margin of discretion, by the public administration, in the selection of non-profit organizations, the determination of the objects and the repeated and common practice of this figure of exceptional nature, which generated the abuse in its application. The National Government, as a result of the improper use of association agreements with private non-profit entities, issued a new regulation comprised in Decree 092 of January 23, 2017, which came into force on June 1 of the same year. This repealed the previous regulations and introduced the application of the principles of government procurement, as well as the design of contractual procedures with plural participation of non-profit organizations in specific cases. This establishes some selection criteria, developed through a guide made by Colombia Compra Eficiente, which, although serving as a guideline and
\end{abstract}


suggestions, lack coercive nature and, therefore, maintain a margin of discretion of the administrative entities that prevents selection based on objective criteria, that is, free from all affection or interest.

Keywords: government procurement, association agreements, non-profit entities, principles, objective selection, transparency.

\section{OS CONVÊNIOS DE ASSOCIAÇÃo COM ORGANIZAÇÕES SEM FINS LUCRATIVOS E SUA INCLUSÃO COMO MODALIDADE NO ESTATUTO GERAL DA CONTRATAÇÃO ESTATAL}

\section{Resumo}

A figura dos convênios de associação tem sua origem no artigo 355 da Constituição política, regulamentado inicialmente pelos decretos 777 e 1403 de 1992 e o decreto 2459 de 1993. Esta normatividade especial é anterior e alheia ao estatuto contratual colombiano, onde se consagrou de maneira particular e pontual o uso dessa tipologia sem definir um procedimento claro para a celebração destes convênios, o que implicou uma ampla margem de discricionariedade, por parte da administração pública, na escolha da ESAL, a determinação dos objetos e a prática reiterada e comum desta figura de caráter exceptivo, o qual gerou o abuso na sua aplicação. O governo nacional, como consequência do uso inadequado dos convênios de associação com organizações privadas sem fins lucrativos, expediu uma nova regulamentação contida no decreto 092 do 23 de janeiro de 2017, que entrou em vigência o $1 .^{\circ}$ de junho do mesmo ano. Com esta derrogaram-se as anteriores regulamentações e se introduz a aplicação dos princípios da contratação estatal, assim como o plano de uns procedimentos contratuais com participação plural das ESAL em casos específicos. Isto determina uns critérios de escolha, desenvolvidos através de uma guia confeccionada pela Colômbia Compra Eficiente, que, se bem servem de pauta e sugestões, carecem de caráter coercitivo e, portanto, mantém uma margem de discricionariedade dos entes administrativos que impede uma escolha baseada em critérios objetivos, isto é, livre de todo afeito ou interesse.

Palavras-chave: contratação estatal, convênios de associação, organizações sem fins lucrativos, princípios, seleção objetiva, transparência. 


\section{Introducción}

En la actualidad, resulta pertinente abordar el tema de las buenas prácticas en la gestión pública (Humbarita, 2015), dado el alto grado de corrupción en la actividad contractual del Estado colombiano, que nos invita a reflexionar, con una mirada crítica y constructiva, sobre los distintos procedimientos o modalidades que se han establecido para el manejo de los recursos públicos (Cortés, 2013). Los principios que rigen dicha actividad deben evidenciar las deficiencias y la necesidad de concebir una nueva estrategia orientada al fortalecimiento de la moralidad y transparencia en los negocios jurídicos en que tenga parte el Estado (Sänger, 2015).

Es por ello que este trabajo de investigación tiene como objeto de estudio la figura de los convenios de asociación con entidades sin ánimo de lucro, de creación constitucional y que corresponden a una práctica permanente y continua de las entidades gubernamentales, como mecanismo de administración del recurso público. Esto ha sido cuestionado no solo por los entes de control, sino por la ciudadanía en general, que observa con indignación la proliferación de entidades sin ánimo de lucro que, aunque no cumplen con las exigencias de reconocida idoneidad y experiencia según consagra la norma constitucional, absorben de manera ilimitada e irresponsable, con anuencia de administraciones de turno, gran cantidad de presupuesto público, sin cumplir la finalidad de la inversión social, base y razón de ser de esta clase de convenios (Blanco, 2015b).

La metodología investigativa que orientó el desarrollo del presente trabajo fue un estudio cualitativo, con enfoque jurídico, de la información referente al tema. Se aplica el método teórico deductivo, a través del análisis y síntesis del material documental, desde fuentes primarias y secundarias. Se tiene en cuenta el referente normativo constitucional, legal y reglamentario, integrado con la jurisprudencia de la Corte Constitucional y del Consejo de Estado, así como la amplia doctrina, artículos científicos publicados en revistas indexadas, trabajos de tesis que abordaron el tema desde diferentes ópticas y que permitieron reafirmar el enfoque y la propuesta delineada en el trabajo investigativo.

\section{El contrato estatal y el convenio de la administración}

Para el desarrollo de este aspecto, se hace necesario abordar los conceptos de contrato estatal y convenio de la administración, y la diferencia existente entre estos dos conceptos, como una forma de marcar el camino hacia el objeto de estudio. 
La actividad estatal, como eje principal de la administración pública, comporta el manejo de los recursos públicos para la consecución de los fines esenciales del Estado, a través de la participación y colaboración de los particulares (Barragán, 2016). Esto genera una actuación de la administración que involucra, en la toma de decisiones, a un tercero. Por una parte, los contratos estatales se dan con la participación de dos o más voluntades; mientras, por otra parte, en los actos administrativos, para garantizar y asegurar su funcionamiento, la toma de decisiones emana únicamente de la voluntad de la administración (Tirado, Bedoya y Blanco, 2016).

Es preciso señalar que las manifestaciones enunciadas, a través de las cuales la administración se vale para el cumplimiento de sus fines, no pueden ser entendidas como diametralmente opuestas. En la actualidad, la complejidad de la actividad pública hace que estos dos mecanismos sean inescindibles y correlacionados (Blanco y Gómez, 2016).

Bajo esta perspectiva, el tratadista Augusto Ramón Marín Chávez (2008), al referirse a los mecanismos utilizados por la administración pública, para el logro de los cometidos estatales, señala:

Para lograr la realización de los cometidos estatales, la administración pública acude a diferentes medios, entre los cuales se destacan aquellos que hacen relación a instrumentos de naturaleza jurídica, como son la producción de actos administrativos y la celebración de contratos. También se destacan los relacionados con recursos de naturaleza humana y económica, que tienen que ver con los empleados del mismo Estado (función pública) y con los bienes que este posee para la obtención de sus fines (patrimonio público).

La actuación que se lleva a cabo mediante actos administrativos implica generalmente la expresión de voluntad del Estado a través de sus propios funcionarios, mientras que la celebración de contratos, por regla general, involucra la colaboración de los particulares, a través de la prestación de servicios, el suministro de bienes o la ejecución de obras. (pp. 41-42)

Ahora bien, en cuanto a los términos de contrato estatal ${ }^{1}$ y convenio de la administración, se ha establecido, desde un punto de vista meramente formal, que el primero es el género, en tanto corresponde a un acto jurídico bilateral que

1 "De los contratos estatales. Son contratos estatales todos los actos jurídicos generadores de obligaciones que celebren las entidades a que se refiere el presente estatuto” (Ley 80, 1993, art. 32). 
implica un acuerdo de voluntades, donde una de las partes es una entidad pública. El segundo, por su parte, es una de las especies, en tanto que, si bien es un acuerdo de voluntades, obedece a una finalidad específica de colaboración, que, enfocada a la administración pública, implica un interés común, diferente a la simple contraprestación propia del contrato (Sarmiento, Medina y Plazas, 2017).

El concepto de contrato estatal recoge, de manera prácticamente similar, la definición de contrato de los artículos 1495 del Código Civil ${ }^{2}$ y 864 del Código de $\mathrm{Comercio}^{3}$, en tanto que básicamente es un acuerdo de voluntades producto del consentimiento, del consenso entre el Estado y sus interlocutores, previo a una verdadera actividad negocial del Estado (González, 2014). Esto deja de lado la concepción de la vieja institución del contrato de adhesión, esto es, la imposición unilateral de la voluntad de la administración ${ }^{4}$ (Rodríguez, 2014).

Existen diversos planteamientos en la doctrina colombiana, como el de Jaime Orlando Santofimio Gamboa, quien sostiene que el estatuto contractual de la administración pública, ley 80 de 1993, regula los contratos interadministrativos y no los convenios interadministrativos, pues de los primeros se derivan obligaciones para las partes, mientras califica los últimos como "simples convenios o acuerdos de la administración, de los cuales no se pueda deducir ningún régimen obligacional”. Es decir, los convenios interadministrativos comportan relaciones jurídicas entre entidades públicas que fundadas en criterios de colaboración, ayuda o cooperación, no corresponden a verdaderos intereses prestacionales, sino que constituyen simples convenciones entre sujetos administrativos o entidades estatales (Quiroz, 2014).

Si bien la ley 80 de 1993 no hace mención a la categoría de convenios, toda vez que solo contempló la figura del contrato interadministrativo, es claro que, por tratarse de un acuerdo de voluntades entre sujetos de naturaleza pública, su esencia y finalidad debía orientarse al interés común y al cumplimiento de los propósitos

2 "Contrato o convención es un acto por el cual una parte se obliga para con otra, a dar, hacer o no hacer alguna cosa." (Código Civil, art. 1495). 2000 Legis Editores S.A.

3 "El contrato es el acuerdo de dos o más partes para constituir, regular o extinguir entre ellas una relación jurídica patrimonial.” (Código de Comercio, art. 864). 2017 Legis Editores S.A.

4 Tesis de la doctrina alemana que se atribuye a los trabajos del profesor Otto Mayer, quien sostenía la imposibilidad de la existencia de contratos entre el Estado y los particulares, en razón de la diferencia en la naturaleza y categoría de las partes. Dado que, para el autor, el contrato presupone sujetos jurídicos de la misma categoría, resulta imposible que el Estado, en tanto sujeto de derecho público, que implica siempre subordinación y fuerza vinculante unilateral frente a los particulares, establezca un contrato con un particular. 
estatales consagrados en la Constitución política, por encima del carácter prestacional y oneroso que caracteriza los contratos.

La palabra convenio proviene del latín conveniere, verbo convenir que significa acordar, estar de acuerdo, concordar, coincidir causando obligación. Esto permite deducir que, desde el punto de vista simplemente formal, contrato y convenio obedecen a un acuerdo de voluntades que genera obligaciones.

La ausencia de regulación del convenio interadministrativo, y la práctica usual de este mecanismo de colaboración entre entidades estatales, hizo que, por vía jurisprudencial, se asimilara el contrato interadministrativo y el convenio interadministrativo, como generadores de obligaciones, estableciendo la esencia de los mismos en la categoría de los sujetos intervinientes y no de la modalidad utilizada para la celebración de los mismos, como lo señaló la Sala plena de la Corte Constitucional en sentencia del 28 de octubre del 2015 (Corte Constitucional, Sentencia C-67/15, 2015).

En ese mismo sentido, el 23 de junio de 2010, la Sección tercera de la Sala de lo contencioso administrativo del Consejo de Estado profirió una sentencia en la que se consideró que los conceptos de convenio interadministrativo y contrato interadministrativo eran iguales (Consejo de Estado, Sección Tercera, sentencia 23/06/2010, 2010).

Si bien la Corte Constitucional asimiló los conceptos de contrato y convenio interadministrativo, por la calidad de los sujetos de la relación negocial (entidades de carácter público), se destaca la diferencia entre el objeto o la finalidad que persiguen. Aunque ambos surgen de un acuerdo de voluntades, tratándose de contratos, hablamos de contraprestación y, por ende, intereses opuestos, mientras que el convenio involucra la colaboración mutua, la unión de esfuerzos para el cumplimiento de fines de interés común.

El convenio de la administración se celebra entre personas jurídicas públicas, o entre estas y los particulares, lo que indica que siempre una de las partes debe ser una entidad de carácter público. Por lo tanto, en la celebración pueden concurrir personas jurídicas públicas del orden nacional, tanto del sector central como descentralizado, así como entidades territoriales y las que corresponden a su sector descentralizado. 


\section{Diferencia entre contrato estatal y convenio de la administración}

Como se ha venido señalando, el contrato estatal se caracteriza por el acuerdo de voluntades con prestaciones recíprocas, en el que las partes tienen intereses propios e independientes. Por su parte, el convenio de la administración busca satisfacer un interés común (Santos Rodriguez, 2009), una finalidad pública, en donde no hay onerosidad, ni contraprestación. En consecuencia, el convenio se basa en la colaboración y cooperación o interés entre las partes, y en esta medida se comparten las actividades, que pueden ser aporte de dinero, de una parte, $y$ de trabajo (aporte en especie), de la otra.

El contrato estatal es conmutativo, razón por la cual se tiene en cuenta la igualdad y el equilibrio entre prestaciones y derechos, principio de interpretación de los contratos estatales, consagrado en el artículo 28 de la ley 80 de 19935. Mientras que, en el convenio de la administración, no se exige la equivalencia entre las obligaciones asumidas por las partes, por cuanto no existen contraprestaciones recíprocas, por la ausencia de conmutatividad.

En el contrato estatal, se debe garantizar el equilibrio económico durante toda la ejecución del contrato (Rodriguez Rodriguez, 2011), el rompimiento del mismo genera la obligación, por parte del Estado, de restablecerlo. En el convenio de la administración, este principio no se aplica, pues, al no existir contraprestación ni onerosidad, no se podría configurar desequilibrio económico alguno.

La justicia arbitral coincide en las anteriores diferencias sobre convenio y contrato estatal. En uno de sus pronunciamientos, señala:

En el contrato estatal se aplica la institución de la conservación del equilibrio contractual, que obliga a la entidad estatal a restablecerla en caso de que se rompa por razones no imputables al contratista, generándose en consecuencia la posibilidad de pagar indemnizaciones o compensaciones a favor del contratista por la ruptura económica del contrato por causas no imputables a este. En el convenio no existe la posibilidad, puesto que ninguna de las entidades signatarias le presta un servicio a la otra, ni mucho menos existe una remuneración por el servicio prestado, lo que

"Artículo 28. De la interpretación de las reglas contractuales. [...] se tendrá en consideración los fines y los principios de que trata esta ley, los mandatos de la buena fe y la igualdad y equilibrio entre prestaciones y derechos que caracterizan a los contratos conmutativos". 
excluye la posibilidad de la ruptura del equilibrio económico financiero del convenio. (Perdomo Guerrero, 2014, p. 35)

En España, sin pretender ahondar en el derecho comparado, es preciso señalar que, como lo ha sostenido García de Enterría y Fernández (2011), en su Curso de derecho administrativo, existe una marcada diferencia entre convenio interadministrativo y contrato interadministrativo. Esto se evidencia por la normatividad que regula cada materia de manera independiente, en la medida en que los primeros se remiten al derecho de la organización, mientras que el último se regula por el estatuto contractual de la administración, es decir, por el ordenamiento regulador de los contratos celebrados entre la administración y los particulares (Fernández Rodríguez y García de Enterría, 2011).

\section{Tipología de convenios de la administración}

El convenio de asociación sin ánimo de lucro es una de las tipologías de los convenios de la administración. Resulta pertinente hacer mención de los demás tipos de convenios de que el Estado se vale para el cumplimiento de sus fines, sin profundizar en el tema, para no desviarnos del objeto de estudio. Como dos grandes vertientes, se encuentran: los celebrados entre personas jurídicas públicas, que son los llamados por el legislador contratos interadministrativos, y que la jurisprudencia asimiló a los convenios interadministrativos; y los celebrados entre las entidades públicas con particulares, convenios donde una parte es el ente público y la otra, el particular sin ánimo de lucro (Blanco, 2012).

Así, la normatividad y la doctrina han establecido una serie de tipologías, que se ubican en los dos grupos enunciados, tales como: convenios con organismos internacionales, convenios de apoyo, convenios de asociación entre entidades públicas, convenios de asociación con particulares sin ánimo de lucro, convenios especiales de cooperación, y convenios de asociación para adelantar actividades científicas y tecnológicas.

\section{Convenios de asociación. Naturaleza jurídica}

El Estado, en su evolución histórica, ha tenido diferentes concepciones respecto al papel de los particulares en la gestión estatal. En el contexto del Estado social 


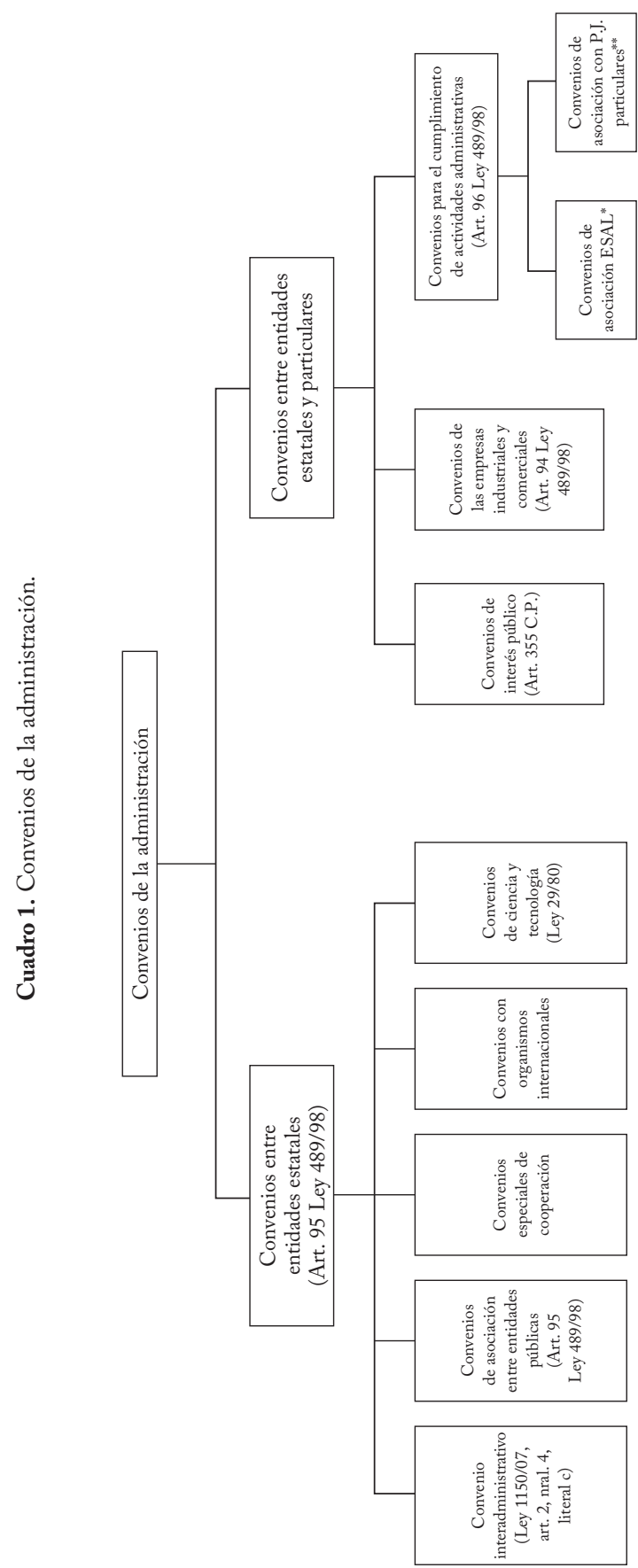


de derecho, se concibe al individuo inmerso en la sociedad, que pasa de ser un receptor de los beneficios del Estado, para participar en la conformación, desarrollo y gestión del mismo. Este se convierte en un actor protagónico de la gestión pública, pues procura el bien común y colabora activamente en la consecución de los fines del Estado.

En ese mismo sentido, Álvaro Tafur Galvis afirma que los particulares no pueden ser considerados sujetos pasivos o antagonistas de las actividades públicas, premisa fundamental en la concepción de un nuevo modelo de gestión pública con participación activa de los particulares. Esto se traduce en la cooperación, colaboración y asociación de entidades públicas con particulares.

En el contexto del Estado social y democrático de derecho, formulado en la Constitución política de 1991, la sociedad, el Estado y las personas consideradas individualmente, ostentan funciones y tareas propias. No obstante, es evidente que a todos ellos caben deberes y funciones comunes en cuanto al progreso y bienestar de la comunidad.

Los particulares no son simplemente sujetos pasivos de la acción estatal, ni sus antagonistas. Es que, orden público aparte, el bien común no es un asunto solo del Estado, sino de los ciudadanos organizados para tal fin. La iniciativa privada, y sobre todo la iniciativa individual, puntualiza el profesor Pomey, tiene sus responsabilidades respecto del interés general; "el bien común es asunto de todos y cada uno, conforme a su nivel de competencia” (Perdomo Guerrero, 2014)

Así las cosas, la gestión pública tiene su mayor desarrollo a través de la contratación estatal, que fundamentalmente se lleva a cabo por la celebración de contratos con particulares, para la consecución de los fines del Estado, dentro de un juego de competencia de los actores del mercado del sector económico que corresponda, en condiciones de igualdad de oportunidades, convocatoria pública y reglas claras y justas, que garanticen la selección objetiva en la escogencia de la oferta más favorable a los intereses de la entidad pública contratante, con miras a que responda a la necesidad que se pretende satisfacer con dicha contratación.

E1 Estado, orientado al cumplimiento de sus fines, de promover la prosperidad general e incentivar la participación de los particulares en la actividad administrativa, utilizó el apoyo en las entidades de beneficencia y utilidad común, como el mecanismo para el logro de dicho propósito. Se entrega, para este efecto, a las instancias públicas como el Congreso, las Asambleas Departamentales y los Concejos, la facultad para que, a través de leyes, ordenanzas y acuerdos, fomenten 
las empresas de utilidad común o beneficencia, que merecieran ser objeto de este apoyo. Este reconocimiento, que viene desde la Constitución de 1886, se afianza con los actos legislativos de 1945 y 1968 (Cortés, 2016).

Empero, esa práctica se pervirtió con el tiempo y se convirtió en un medio para que se aprovecharan de los recursos públicos con fines distintos a los que el Estado se había propuesto. En consecuencia, se ha convertido en uno de los mayores focos de corrupción en el país, que enriquece a los parlamentarios o financia sus campañas electorales, lo cual hizo visible la ausencia de mecanismos de control adecuados y eficaces sobre la inversión de los recursos. Esto generó que el constituyente de 1991 respondiera a las voces de rechazo de importantes sectores de la opinión pública, con la decisión de eliminar los denominados auxilios parlamentarios no solo a nivel del Congreso, sino de las demás corporaciones públicas de elección popular.

Como mecanismo de control frente al mal manejo que se le venía dando a los recursos públicos destinados a las actividades de fomento, el artículo 355 de la Constitución política no solo prohíbe de manera expresa los auxilios parlamentarios o donaciones a entidades de derecho privado, sino que consagra un régimen de contratación que autoriza a las entidades de orden nacional, departamental, distrital y municipal la celebración de contratos con entidades sin ánimo de lucro y de reconocida idoneidad, siempre y cuando tengan como finalidad impulsar programas y actividades de interés público, acordes con el plan nacional y los planes seccionales de desarrollo.

El inciso segundo del artículo 355 otorga la facultad al Gobierno nacional de reglamentar la materia. En efecto, a través de los decretos 777 y 1403 de 1992 y 2459 de 1993, el Gobierno estableció las condiciones, requisitos y formalidades que se deben cumplir para la celebración de los contratos con entidades sin ánimo de lucro y de reconocida idoneidad, así como los contratos que se encuentran excluidos de su aplicación.

El concepto de asociación aparece con la ley 489 de 1998, que nace para regular la función administrativa, determinar la estructura y definir las reglas básicas de organización y funcionamiento de la administración pública. Se establecen diferentes tipos de asociaciones, entre las que se encuentran: el convenio de delegación de funciones ${ }^{6}$, el convenio de asociación entre entidades públicas, los convenios de desempeño y, de manera general, los convenios de organización.

6 "Delegación entre entidades públicas. La delegación de las funciones de los organismos y entidades administrativas del orden nacional, efectuada en favor de entidades descentralizadas o entidades 
En el derecho público, no resulta novedoso el término asociación, en la medida en que ya ha sido utilizado en temas relacionados con telecomunicaciones e hidrocarburos, como los convenios de asociación celebrados por la Empresa Colombiana de Petróleos - Ecopetrol. Además, en el artículo 7 del Estatuto General de la Contratación Pública (Ley 80,1993), se establece la posibilidad de que los particulares se asocien, a través de una unión temporal o consorcio, para la celebración de un contrato con entidades estatales (Chávez Marín, 2008).

La ley 489 de 1998 consagra diferentes modalidades de asociación. En los artículos 94, 95 y 96, crea nuevas figuras, entre las que se encuentra el convenio de asociación con entidades privadas sin ánimo de lucro. En el artículo 96, se contempla la constitución de asociaciones y fundaciones para el cumplimiento de las actividades propias de las entidades públicas con participación de particulares.

Los convenios de asociación a los que se refiere el citado artículo, cuando se celebren con entidades privadas sin ánimo de lucro, deben dar aplicación no solo a lo dispuesto por el artículo 355 de la Constitución política, sino también a las reglas que conforme al ordenamiento jurídico desarrollan esta disposición. Esto indica que, tratándose de esta clase de convenios, la citada normativa prevé la remisión a la norma constitucional.

La Corte Constitucional en sentencia C-671 de 1999, al declarar exequible el artículo 96 de la ley 489 de 1998, manifiesta que la remisión ordenada ha de entenderse con dos fines. El primero es en defensa de la transparencia en el manejo de los recursos públicos, esto es, que no podrá excusarse en la celebración de los convenios de asociación para otorgar o decretar auxilios o donaciones a favor de personas naturales o jurídicas de derecho privado. El segundo se traduce en una imposición a la celebración de contratos con entidades sin ánimo de lucro y de reconocida idoneidad, empero con el objetivo de impulsar programas y actividades de interés público acordes con el plan nacional y los planes seccionales de desarrollo, como lo dispone el artículo 355.

El Gobierno nacional, en uso de la facultad de reglamentación conferida en el artículo 355, profiere el decreto 092 del 27 de enero de 2017, por el cual se reglamenta la contratación con entidades privadas sin ánimo de lucro. A esto hace

territoriales, deberá acompañarse de la celebración de convenios en los que se fijen los derechos y obligaciones de las entidades delegantes y delegataria [...]. Estos convenios estarán sujetos únicamente a los requisitos que la ley exige para los convenios o contratos entre entidades públicas o interadministrativos." (Ley 489, 1998, art. 14). 
referencia el inciso segundo del artículo 355 de la Constitución política, que deroga los decretos 777 de 1992, 1403 de 1992 y 2459 de $1993^{7}$.

Si bien se introducen algunas modificaciones, tendientes a que la contratación con entidades privadas sin ánimo de lucro cumplan la finalidad con que fueron creadas por el constituyente de 1991, es preciso señalar que bajo la reglamentación de los decretos 777 y 1403 de 1992, pese a que se establecieron requisitos y condiciones para la celebración de dichos convenios, estos resultaron insuficientes para evitar que se abusara de esta figura, desviando los recursos y dándole un uso distinto al propuesto, con el objeto de eludir los procesos de selección contemplados en el Estatuto General de la Contratación Pública.

La nueva reglamentación trae algunas prácticas para dar transparencia y objetividad a la selección, previstas en el Estatuto General de la Contratación Pública, como se evidencia en el artículo 4 del decreto 092 de 2017. No obstante, al establecer un proceso competitivo de selección cuando existe más de una entidad sin ánimo de lucro de reconocida idoneidad, aunado a la exigencia de la observancia de los principios que rigen la contratación estatal, la nueva reglamentación resulta aún precaria, pues mantiene esta figura ajena a las modalidades existentes en el régimen contractual del Estado. Esta sería una solución para contar con una verdadera herramienta que garantice la selección objetiva, y la participación en condiciones de igualdad y pluralidad entre los gestores públicos particulares, lo que permitiría no solo el cumplimiento de la actividad de impulso y fomento del Estado a las entidades solidarias, sino que también garantizaría la eficiencia del gasto público y la redistribución equitativa.

\section{Criterios para la estructuración de un procedimiento contractual en los convenios de asociación, que permita la aplicación de los principios de transparencia y selección objetiva, bajo una modalidad propia}

Las reglamentaciones de los convenios de asociación, que se han realizado por parte del Gobierno nacional, se caracterizan por fijar criterios que no permiten

\footnotetext{
"Artículo 11. Vigencia y derogatorias. El presente decreto empieza a regir el 1o de junio de 2017 y deroga el decreto 777, el decreto 1403 de 1992 y el decreto 2459 de 1993. Los contratos suscritos antes de la entrada en vigencia del presente decreto continuarán ejecutándose de acuerdo con las normas vigentes en el momento en que fueron suscritos."
} 
la escogencia de las entidades sin ánimo de lucro, en adelante (ESAL), en garantía de los principios de la contratación estatal, especialmente los de transparencia y selección objetiva.

Esto persiste, a pesar de la actual reglamentación, que si bien consagró expresamente que la figura jurídica debía someterse a los principios del Estatuto General de la Contratación Pública, no estableció ni desarrolló criterios objetivos que permitieran, a través de un proceso de selección propio y acorde con la naturaleza misma de esta tipología de contratos, escoger la ESAL más favorable para cumplir con la actividad de fomento del Estado, en procura de satisfacer las necesidades de interés público y social, y mucho menos plantear o proponer la inclusión de este proceso concursal como una quinta modalidad de selección dentro del Estatuto General de Contratación Pública, como es el objetivo de este trabajo investigativo (Patarroyo \& Benavides, 2014).

Así las cosas, se concretará la propuesta de inclusión de una quinta modalidad de selección para los contratos de interés público y convenios de asociación. Se determina la aplicación de los siguientes criterios, que contribuyen a la fijación de reglas claras para la escogencia de la entidad sin ánimo de lucro, acorde con la naturaleza y tipología especial que reviste esta clase de relación contractual:

- La reconocida idoneidad de la entidad privada sin ánimo de lucro: Este requisito se constituye como el eje central y determinante en la escogencia de la ESAL más favorable para el cumplimiento de la finalidad que persigue la actividad de fomento. Así, el mismo constituyente lo erigió como característica inherente para esta tipología contractual. De ahí que los criterios e indicadores para calificar este requisito deben contener elementos objetivos que permitan la selección en igualdad de condiciones, pluralidad de potenciales oferentes y buscando solo el interés general y el beneficio social que se persigue.

- Concordancia del objeto misional de la esal con el objeto a contratar: Se requiere que el objeto de la ESAL esté acorde con los programas y planes de desarrollo de las entidades del orden nacional, seccional y local, en concordancia con lo dispuesto en el artículo 355 constitucional.

Para cumplir con este parámetro, no solo basta con que se revise la concordancia del objeto a contratar con el objeto misional de la EsAL, esta debe contar con los soportes correspondientes que acrediten los resultados frente a la actividad misional llevada a cabo durante mínimo dos años. 
- Experiencia: La entidad estatal, independientemente de la complejidad del proyecto y el valor del convenio o contrato, evaluará que la entidad privada sin ánimo de lucro cumpla con la trayectoria mínima exigida ( 2 años) en el desarrollo del objeto acorde con el que se pretende contratar ${ }^{8}$, durante el período de existencia de la EsAL.

- Capacidad jurídica: La eSAL deberá demostrar su capacidad jurídica con los siguientes documentos: acta de constitución y estatutos debidamente aprobados e inscritos ante la autoridad correspondiente, certificado de inscripción en el Registro Único de Proponentes (RUP) e inscripción en el Sistema Electrónico para la Contratación Pública SECoP II.

- Capacidad organizacional: Se entiende como la aptitud de un proponente para cumplir oportuna y cabalmente el objeto del contrato, en función de: su organización interna, su eficiencia administrativa y su capacidad de mantenerse bajo niveles de óptimo funcionamiento, solidez financiera y eficaz prestación de las actividades misionales en beneficio social ${ }^{9}$.

- Capacidad técnica: Este factor se encuentra asociado a la experiencia específica en el desarrollo del objeto misional concordante con el objeto contractual requerido por la entidad pública. Dada la presentación de contratos, convenios y/o proyectos o eventos, deben constar las actividades desarrolladas, el presupuesto, el número de beneficiarios, la actividad administrativa, operativa y misional desplegada por la ESAL.

- Indicadores de eficiencia de las ESAL: En este factor, resulta procedente aplicar los índices planteados en la Guía de Colombia Compra Eficiente CCE, que muestran los indicadores financieros asociados a la eficiencia de la entidad sin ánimo de lucro, demostrando su grado de madurez y dedicación a proyectos misionales.

8 En la guía elaborada por Colombia Compra Eficiente ( $\mathrm{CCE}$ ), la experiencia se evalúa teniendo en cuenta la complejidad del proyecto, la cantidad de recursos que se comprometen y los riesgos a los que está sometido el desarrollo del mismo, lo que deja que la entidad estatal determine la aplicación de esos factores y con ellos la exigencia a requerir. Esta circunstancia rompe con la objetividad que se busca, y precisamente los tres índices que enuncia pueden ser valorados a través de los otros factores objeto de verificación o evaluación.

9 La entidad estatal solicitará evidencias a efectos de constatar que la entidad privada sin ánimo de lucro cuenta con el equipo misional, técnico y administrativo necesario para cumplir con el programa o actividad del plan de desarrollo, y con la capacidad de adaptarse rápidamente, vinculando y entrenando nuevas personas. 
La administración de la entidad privada sin ánimo de lucro debe mostrar eficiencia en el gasto, para lo cual es útil el siguiente indicador sobre la eficiencia en la administración de la totalidad de sus proyectos:

Gastos de implementación de los proyectos en el año $x$

Total gastos de funcionamiento de la ESAL en el año $x$

Entre mayor sea este porcentaje, más recursos utiliza la entidad privada sin ánimo de lucro para satisfacer las necesidades de la comunidad y menos en su propia administración.

Dado que las contribuciones estatales a las entidades privadas sin ánimo de lucro pueden desplazar las donaciones provenientes del sector privado y reducir los incentivos para buscar financiación privada ${ }^{10}$, es recomendable tener en cuenta un indicador de eficacia del esfuerzo de la ESAL para conseguir contribuciones del sector privado:

Total gastos de funcionamiento de la ESAL en el año $x$

Total de contribuciones del sector privado en el año $x$

El resultado mostrará las evidencias de la efectividad del desarrollo de las actividades misionales de la ESAL y del cumplimiento de sus objetos contractuales. Estos índices deberán estar contenidos en el RUP, mediante el aplicativo que se utilice para su verificación, lo que permite que la entidad contratante solicite los documentos contables, balance general y estados financieros de los dos años inmediatamente anteriores al proceso contractual, debidamente avalados por el contador público o revisor fiscal, según corresponda.

- Resultados meritorios: Este factor corresponde al llamado reconocimiento o reputación de la entidad, inherente a su reconocida idoneidad, que es la trayectoria en el desarrollo de su objeto misional, con resultados satisfactorios, visibles y medibles, que reflejen el beneficio social que prestan.

Lo anterior hace necesario que la entidad estatal, al terminar la ejecución o desarrollo del proyecto, evalúe la efectividad de la ESAL en la ejecución. Para esto se tendrán en cuenta los resultados de la intervención y las dificultades encontradas en el desarrollo del proyecto, así como la eficacia de los mecanismos de verificación que fueron empleados, con participación de la comunidad beneficiaria. El documento de evaluación, que para el efecto

10 Véase Nikolova (2015), Andreoni y Payne (2011), y la guía de Colombia compra eficiente (2017). 
se elabore, debe ser publicado en el sEcop y ser considerado por las demás entidades estatales cuando contraten con ESAL.

- Régimen tributario: En razón de la proliferación de las ESAL, por la falta de control en el aspecto tributario, el Gobierno nacional expidió el nuevo régimen tributario especial, al que deben acogerse las fundaciones, organizaciones, corporaciones y entidades sin ánimo de lucro, para lo cual deberán reportar toda su información financiera a la Dirección de Impuestos y Aduanas Nacionales (DIAN).

- Riesgos del proyecto: La entidad contratante deberá efectuar una matriz de riesgos en la ejecución del contrato, que establezca la responsabilidad en porcentaje correspondiente a las partes contratantes, la cual deberá concertarse con la ESAL, a través de una audiencia obligatoria de estimación y asignación de riesgos. Para la elaboración de esa matriz, se debe tener en cuenta la naturaleza y complejidad del objeto a contratar, el presupuesto, el plazo y el grado de vulnerabilidad de la población beneficiada.

- Del control ciudadano: Deberán ser convocadas las veedurías ciudadanas, como mecanismo democrático de representación, que permite a los ciudadanos, o a las diferentes organizaciones comunitarias, ejercer vigilancia sobre los procesos de selección de una ESAL, aplicando la ley 850 de 2003 en los términos contemplados en el Estatuto de la Contratación (artículo 66).

\section{De la inclusión como quinta modalidad en el Estatuto General de la Contratación Estatal}

La ley 1150 de 2007, modificatoria de la ley 80 de 1993, estableció en su artículo 2 las modalidades de selección a través de las cuales el Estado puede contratar los bienes y servicios necesarios para el cumplimiento de los fines y garantía del interés general, como principio fundamental que debe orientar la gestión pública y el adecuado y correcto manejo del presupuesto estatal.

Así mismo, la ley 80 y la ley 1150 se ocuparon de integrar, en el Estatuto General de la Contratación Estatal, todas las tipologías: las comunes, generales o propias del Estado; y las especiales, que tienen su propia regulación y no puede aplicárseles el estatuto, pero que en últimas deben sujetarse a los principios de la función administrativa, contemplados en los artículos 209 y 267 de la Constitución y la ley (Blanco, 2015a). 
El Gobierno nacional, conforme a la facultad otorgada por el constituyente primario en el inciso segundo del artículo 355, adquiere la competencia para dictar un reglamento autónomo, atendiendo el criterio de especificidad y con interpretación restrictiva, para regular todo lo concerniente a la modalidad contractual prevista en dicha norma, sin desconocer la reserva legal general que corresponde al Congreso de la República. Esto indica que el Gobierno por expreso mandato constitucional, no necesita ningún otro mecanismo legal para integrar como una quinta modalidad los convenios de asociación en caso que lo considere, al Estatuto General de la Contratación Estatal (Millán, Blanco y Guecha, 2017).

Resulta conveniente, entonces, que la contratación con las entidades privadas sin ánimo de lucro se haga conforme a los parámetros de una quinta modalidad de contratación, acorde con la naturaleza misma de las entidades participantes y el objeto contractual propio de esta tipología, que busca el beneficio de la comunidad en condiciones de vulnerabilidad (Palomares y Calonje, 2015) y debe materializar los objetivos, planes y metas de la inversión social contenida en el plan nacional y en los planes seccionales de desarrollo.

La quinta modalidad deberá hacer referencia a la contratación con entidades privadas sin ánimo de lucro, tanto para el impulso de programas de interés social, acordes a los planes y programas de desarrollo de las entidades de orden nacional, seccional y local, como para los convenios de asociación para desarrollar actividades propias de las entidades públicas; bajo la normativa constitucional del artículo $355 \mathrm{y}$ el artículo 96 de la ley 489 de 1998, respectivamente. Para el efecto, se debe definir cada una de las reglas y criterios para la escogencia de la entidad ejecutora, eliminando la remisión a pautas o sugerencias contenidas en una guía de contratación que no tiene el carácter coercitivo, lo que a la larga evita que sean las entidades las que en últimas definan los aspectos no concretos o específicos, es decir, evita que terminen siendo criterios subjetivos, en vez de criterios objetivos que garanticen la aplicación de los principios de transparencia y selección objetiva (Pardo, 2014).

Con la práctica de una sana competencia entre las ESAL, se puede llegar a construir una verdadera conciencia de la utilidad que estas prestan en la consecución de los fines del Estado. Además, se promueve una real contribución del sector sin ánimo de lucro, sin que implique la sola búsqueda de la financiación estatal, sino que esté orientada a la función social, a servir de mediadores entre las personas en condición de desventaja social y la administración pública, reivindicando y denunciando las situaciones de exclusión social, sensibilizando a la población en general, 
detectando y alertando de las nuevas necesidades y problemas sociales, con una estructura dinámica que dé respuesta con mayor rapidez que la propia administración (Joera Sozialak eta gizarteratzea, 2010, pp. 137-144).

\section{Conclusiones}

En el desarrollo normativo de la actividad contractual, para el manejo de los recursos estatales y la búsqueda de la eficiencia de la gestión pública, escapó por más de 25 años la figura de los convenios de asociación. Su origen se remonta a la Constitución política que los consagra en su artículo $355^{11}$, reglamentado en su primera etapa por los decretos 777, 1403 de 1992 y 2459 de 1993, y en la actualidad por el decreto 092 de 2017.

Si bien el Gobierno nacional, al expedir el decreto 092 de 2017, hizo un intento por armonizar los convenios de asociación al Estatuto General de la Contratación Pública y a los principios que lo rigen, fue tímido en la estructuración de un proceso de selección propio y autónomo para esta tipología contractual, y en determinar de manera específica unos criterios que garantizaran la selección objetiva de la ESAL más idónea y conveniente para el cumplimiento del objeto contractual en beneficio social de la población más vulnerable; con un eficiente y eficaz gasto público en desarrollo de su actividad de fomento o impulso de las organizaciones no lucrativas, para el cabal cumplimiento de su misión de servicio comunitario.

No obstante, los altos fines que comportan la actividad del tercer sector o sector no gubernamental solidario, la aplicación de la figura de los convenios de asociación ha estado permeada por prácticas corruptas. Estas devienen no solo del sector estatal, sino también de las mismas entidades privadas sin ánimo de lucro, que han proliferado no por los fines altruistas que las deben caracterizar, sino como un mecanismo para defraudar y despilfarrar el erario.

Resulta recurrente que el uso desbordante de esta figura se dé por la falta de una reglamentación armónica con los postulados y principios que gobiernan la gestión negocial del Estado. Esto puede justificarse por la regulación inicial, en la medida

11 "Ninguna de las ramas y órganos del poder público podrá decretar auxilios o donaciones a favor de personas naturales o jurídicas de derecho privado. El gobierno, en los niveles nacional, departamental, distrital y municipal, podrá, con recursos de los respectivos presupuestos, celebrar contratos con entidades privadas sin ánimo de lucro y de reconocida idoneidad, con el fin de impulsar programas y actividades de interés público, acordes con el plan nacional y los planes seccionales de desarrollo. E1 Gobierno Nacional reglamentará la materia" (Const., 1991, art. 355). 
en que fue expedida en vigencia del régimen contractual del decreto 222 de 1983, que no contaba con una normatividad unificada ni tenía consagrados principios rectores como los concibió la ley 80 de 1993, el Estatuto General de la Contratación Estatal vigente.

Por lo anterior, es inexplicable, y por demás cuestionable y reprochable, que el Gobierno nacional, después de dos décadas y media de promulgarse el régimen actual de contratación pública, expidiera el decreto reglamentario 092 de 2017, que consagró, para los convenios de asociación, la aplicación de los principios de la contratación estatal. Esta exigencia, desde la asamblea nacional constituyente de 1991, se previó como mecanismo para erradicar, de una vez por todas, las donaciones o auxilios parlamentarios. Realizar la actividad de fomento del Estado mediante contratos implica desarrollar una actividad reglada, participativa y con eficiencia y eficacia en la inversión de los recursos estatales.

Una reglamentación que verdaderamente armonice esta tipología con el Estatuto General de Contratación Pública debe contemplar un proceso competitivo general y reglado, con la determinación de etapas y criterios que garanticen la participación igualitaria de las ESAL; debe permitir la optimización y/o racionalización del gasto público. Sin embargo, el decreto 092 de 2017 refleja la falta de voluntad política del Gobierno nacional para erradicar de forma tajante el uso inadecuado y la discrecionalidad en el manejo de los recursos de inversión, en esta clase de contratación.

Es por ello que resulta consistente y pertinente la propuesta que se planteó en este trabajo investigativo, a fin de lograr que los convenios de asociación con entidades privadas sin ánimo de lucro cumplan con el fin primordial del Estado: servir a la comunidad, garantizando la aplicación de los principios de transparencia y selección objetiva. Se trata de la inclusión de esta tipología contractual como una quinta modalidad de selección en el Estatuto General de la Contratación Pública, definiendo reglas que respondan a su naturaleza y garanticen los principios enunciados, así como el cumplimiento de los fines de interés social con la participación efectiva de la sociedad en el control y vigilancia de los mismos.

Esta quinta modalidad de selección debe estructurarse con criterios que permitan la escogencia objetiva de la ESAL más favorable para la satisfacción del beneficio social que se persigue con la actividad de fomento estatal. Se debe cumplir con los principios de transparencia y selección objetiva en esta tipología contractual, para superar el abuso de la figura, que ha conllevado el despilfarro de los dineros 
estatales, y, lo más ignominioso, la burla a la población más desprotegida y vulnerable de la sociedad.

\section{Referencias}

Andreoni, J. y Payne, A. A. (2011). Is Crowding Out Due Entirely to Fundraising? Evidence from a Panel of Charities. Journal of Public Economics, 95(5), 334-343.

Barragán, D. (2016). La construcción de la mentalidad democrática como necesidad en el posconflicto. Revista Via Inveniendi et Iudicandi, 11(1), 37-57.

Blanco, C. (2012). La descentralización colombiana en el marco de la comunidad andina. Revista Estudios de Derecho, 69(153).

Blanco, C. (2015a). La cláusula de renegociación en los contratos de concesión de obra pública. Revista Republicana, 19, 56-78.

Blanco, C. (2015b). La influencia positiva de la caN en la descentralización territorial colombiana. Revista Opinión Jurídica, 14(27). Recuperado de https://revistas.udem. edu.co/index.php/opinion/article/view/1204

Blanco, Carolina. y Gómez, Dilia. (2016). Constitución política e integración andina desde las nociones de soberanía y democracia. En Perspectivas críticas del derecho constitucional colombiano. Bogotá, Colombia: Universidad Libre, 56-78.

Chávez Marín, A. R. (2008). Los convenios de la administración: entre la gestión pública y la actividad contractual. Bogotá: Universidad del Rosario.

Colombia compra eficiente. (2017). https://www.colombiacompra.gov.co/manuales-y-pliegos-tipolmanuales-y-guias

Corte Constitucional. (1999). Sentencia C-671.

Cortes, S. (2013). La globalización económica y los derechos humanos. Revista Via Inveniendi et Iudicandi, 8(2).

Cortes, S. (2016). Derechos humanos en las políticas de paz y posconflicto en Colombia. Revista Via Inveniendi et Iudicandi, 11(1), 129-145. Recuperado de http://revistas. usantotomas.edu.co/index.php/viei/article/view/2926/2798

Fernandez Rodriguez, R. y García de Enterría, E. (2011). Curso de Derecho Administrativo. Civitas (Fernandez Rodriguez \& García de Enterría, 2011) (Fernandez Rodriguez \& García de Enterría, 2011), Bogotá, Editotial Temis. 
González, O. (2014). La Corte Constitucional como agente del campo jurídico colombiano: la omisión legislativa de principios constitucionales. Revista IUSTA, 41(2), 123-137.

Humbarita, J. (2015). Derecho constitucional hispanoamericano frente a la realidad institucional, manifiesta divergencia. Revista IUSTA, 43(2), 56-78.

Joera Sozialak eta gizarteratzea. (2010). Tendencias sociales e inclusión social. Bilbao, España: Federación Sarto-Área de Consultoria Social.

Millán, J., Blanco, C. y Guecha, C. (2017). Los procesos de selección de operadores privados del servicio público de televisión en torno a la libre concurrencia. En Justicia constitucional (Tomo II) (pp. 199- 221). Recuperado de https://repository.usta.edu.co/ handle/11634/4249

Nikolova, M. (2015). Government Funding of Private Voluntary Organizations Is There a Crowding-Out Effect? Nonprofit and Voluntary Sector Quarterly, 44(3), 487-509.

Palomares, J. y Calonje, N. (2015). Tratados de libre comercio Colombia-Asia: Cuestión preliminar y perfiles de negociación. Revista IUSTA, 43(1), 17-41.

Pardo, N. (2014). Un recorrido por los derechos colectivos en la jurisprudencia argentina. Revista Via Inveniendi et Iudicandi, 9(1), 32-49. Recuperado de http://revistas.usantotomas.edu.co/index.php/viei/article/view/1338/1540

Patarroyo, S. y Benavides, P. (2014). Rupturas asignificantes: Revisiones críticas en torno al derecho. Revista Via Inveniendi et Iudicandi, 9(1), 7-31.

Perdomo Guerrero, C. (2014). Los convenios de la administración y los contratos estatales: conceptos diferentes con regimenes jurídicos distintos. (Tesis de maestría). Universidad Nacional de Colombia, Bogotá, Colombia.

Quiroz, M. (2014). Acercamiento a las “oposiciones paradigmáticas” entre neoconstitucionalismo y positivismo jurídico. Revista IUSTA, 41(2), 77-97.

Rodríguez, A. (2014). Indicadores de constitucionalidad de las políticas públicas: enfoque de gestión de derechos. Revista Via Inveniendi et Iudicandi, 9(2).

Sänger, R. (2015). La garantía de la propiedad y el principio de proporcionalidad como límites de la carga tributaria en Alemania. Revista IUSTA, 42(1), 73-99.

Santofimio Gamboa, J. O. (s.f.). El carácter conmutativo y por regla general sinalagmáctico del contrato estatal y sus efectos respecto de la previsibilidad del riesgo y del mantenimiento de su equilibrio económico, Revista Digital de Derecho Administrativo no. 1, Universidad Externado de Colombia, pp. 1-57. 
Santos Rodriguez, J. E. (2009). Consideraciones sobre los contratos y convenios interadministrativos. Revista digital Derecho, 8.

Sarmiento, D., Medina, S. y Plazas, R. (2017). Sobre la responsabilidad y su relación con el daño y los perjuicios. Revista Via inveniendi et Iudicandi, 12(2), 101-115. DoI: https://doi.org/10.15332/s1909-0528.2017.0002.05

Tirado, M., Bedoya, J. y Blanco, A. (2016). Bioética y transhumanidad: Hacia una aproximación al consumo de sustancias nootropicas en el campo académico. En Bioética y Docencia (pp. 91-119). Bogotá, Colombia: Editorial Ibáñez. Recuperado de https://repository.usta.edu.co/handle/11634/1527. 